\title{
Exergy performance of a new ORC configuration of a solar cogeneration system using a gas ejector
}

\author{
Larbi Afif ${ }^{1, *}$ and Nahla Bouaziz ${ }^{1}$ \\ ${ }^{1}$ Université de Tunis El Manar, Ecole Nationale d'Ingénieurs de Tunis, Unité de Recherche Energétique \\ et Environnement, 1002, Tunis, Tunisie
}

\begin{abstract}
In the context of sustainable development and more particularly the conversion of heat into electricity, the present work proposes a new system of cogeneration operating at low energy value. It's an organic Rankine cycle, associated with a gas ejector and operating with different organic fluids. It should be noted that the development of the ORC technology is partly a well-adapted response to problems of energy saving and ecosystem preservation. Accordingly, this paper presents a new configuration of a cogeneration system operating at low temperature and ensuring the simultaneous production of electricity and refrigeration. The proposed system is operating under transcritical and subcritical regime using solar energy as thermal source. On the other hand, an energy and exergy study has been developed by choosing the refrigerants R124, R236fa, R1234yf and R1234ze as working fluids according to their low environmental impact and thermodynamic properties. The results of the numerical simulation carried out as part of this study have also shown the importance of integrating the ejector into the proposed machine. Indeed, we investigated the effect of the thermodynamic parameters of the ejector on the coefficient of performance and the exergy efficiency of the cogeneration system.
\end{abstract}

\section{Introduction}

Recently, the large consumption of fossil fuels has caused a series of environmental problems such as the global warming. this harming effect on the ecosystem has led many researchers to introduce several technologies like Kalina cycle [1], Goswami cycle [2], TLC (trilateral cycle) [3] and ORCs (Organic Rankine cycles) [4] using cleaner energy at low temperature[5-7].

In fact, the organic Rankine cycle (ORC) is considered as an efficient heat conversion technologies and well adapted for the renewable energy applications such as geothermal [8], biomass [9], waste heat recovery [10] and solar energy [11].

In particular, ORC technology using solar energy is considered as a competitive machine since it presents a lower investment cost by working at lower temperature. On the other hand, scholars have used the ORC system for the cogeneration plants in order to obtain higher energy efficiency [12]. In addition, according to literature [13], concentrating solar power technology like parabolic troughs are suitable for ORC applications and can provide a heat source temperature up to $300^{\circ} \mathrm{C}$.

In this paper, a cogeneration system based on ORC cycle is proposed and assuring the production of electricity power and refrigeration simultaneously. An energy and exergy analysis is made by considering the following assumptions:

- The system heat losses into the environment are negligible.
- The pressure drops of the heat exchangers are negligible.

- The flow across the expansion valves is isenthalpic.

- All cycle processes have reached a steady state condition.

- The ejector processes are assumed to be adiabatic.

- Kinetic and potential energies and exergies are negligible.

\section{System descriptions}

An organic rankine cycle operates the same as the traditional rankine cycle but uses an organic fluid instead of water. This change brings several advantages which will be discussed later in this paper. The cogeneration system proposed is using a parabolic trough as a solar concentrator providing heat power to the steam generator. On the other hand, the ambient air is used as a cooling source for the system.

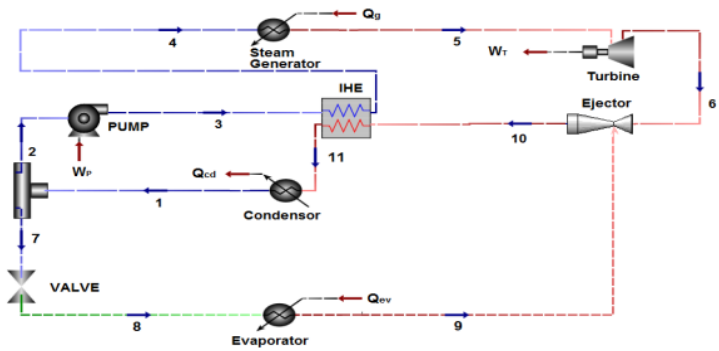

Fig. 1. Configuration of the proposed cogeneration system

\footnotetext{
* Corresponding author: author@e-mail.org
} 
As shown in figure 1 , the cogeneration plant configuration is made by associating an ORC cycle with a refrigeration one. Unlike other refrigeration cycles, the compressor is replaced by a gas ejector to reduce energy consumption. This new organ has the ability to compress thermally the low pressure gas of the refrigeration cycle by using the high pressure gas of the ORC cycle. In fact, an ejector is using convergent and divergent nozzles to convert the high pressure into higher velocity in order to entrain the secondary fluid. In the diffuser chamber, the mixed fluid is recompressed at a medium pressure. The figure 2 shows the different components of the gas ejector.

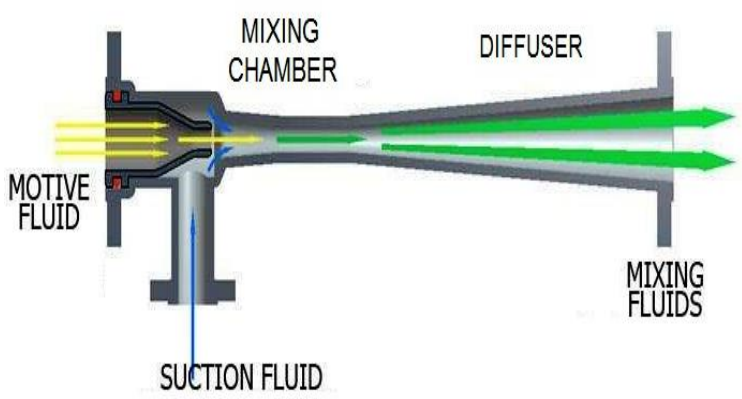

Fig. 2. Geometric Configuration of the gas ejector

\section{Working fluid selection}

The selection of the working fluid has a major effect on the ORC system performance. First of all, the choice of the fluid must be adapted to the operating heat source temperature of the system. In fact, refrigerants are highly recommended for systems operating at low temperature.

Besides, they are considered as dry fluids because their vapor saturation curve has a positive slope in the T$\mathrm{s}$ diagram $[14,15]$. Therefore, the moisture carried by the turbine expansion of the fluid is avoided.

However, the environmental impact must be taken into account by identifying a fluid that has low values of the ozone depletion potential ODP and global warming potential GWP. The chosen fluids in this work are presented in table 1 .

Table 1. Working Fluids Properties

\begin{tabular}{|c|c|c|c|c|}
\hline Refrigerant & $\begin{array}{c}\text { Critical } \\
\text { Temperature } \\
\left({ }^{\circ} \mathrm{C}\right)\end{array}$ & $\begin{array}{c}\text { Critical } \\
\text { Pressure } \\
(\text { Bar })\end{array}$ & GWP & ODP \\
\hline R124 & 124,5 & 36,6 & 609 & 0.02 \\
\hline R236fa & 122,92 & 32,192 & 9810 & 0 \\
\hline R1234yf & 94,7 & 33,82 & 4 & 0 \\
\hline R1234ze & 109,36 & 36,62 & 6 & 0 \\
\hline
\end{tabular}

\section{Energy analysis and modeling}

The software Aspen Hysys had been used in this study for the simulation of the cogeneration system. To evaluate the system performance, the Peng Robinson equation (1) had been chosen as a thermodynamic model for the simulation process since it is highly recommended, essential and relatively irreplaceable for calculations of liquid-vapor equilibrium under pressure of hydrocarbons.

$$
P=\frac{R T}{V_{m}-b}-\frac{a(T)}{V_{m}^{2}-2 b V_{m}-b^{2}}
$$

Where

$$
a(T)=a^{*} \frac{R^{2} T_{c}^{2}}{P_{c}} \alpha(T) \quad \text { And } b=b^{*} \frac{R T_{c}}{P_{c}}
$$

On the other hand, results have shown that the integration of the ejector affects the system performance through the thermodynamic parameters of the gas ejector, as shown in table 2.

Table 2. Thermodynamic Parameters of the Ejector

\begin{tabular}{|c|c|c|}
\hline Symbol & Parameter & Expression \\
\hline$U$ & Entrainment Ratio & $\dot{\mathrm{m}}_{2} / \dot{\mathrm{m}}_{1}$ \\
\hline$\varepsilon$ & Motive Ratio & $\mathrm{P}_{1} / \mathrm{P}_{3}$ \\
\hline
\end{tabular}

The energy analysis of the cogeneration system is made by using the equations shown in table 3 .

Table 3. Energy and Efficiency Equations of the System

\begin{tabular}{|c|c|}
\hline ComponentlEfficiency & Equation \\
\hline Vapor Generator & $Q_{g}=m_{1}\left(h_{5}-h_{4}\right)$ \\
\hline Evaporator & $Q_{E}=m_{2}\left(h_{9}-h_{8}\right)$ \\
\hline Condenser & $Q_{C D}=m\left(h_{1}-h_{11}\right)$ \\
\hline Turbine & $W_{T}=m_{1}\left(h_{6}-h_{5}\right)$ \\
\hline Pump & $W_{P}=m_{1}\left(h_{3}-h_{2}\right)$ \\
\hline Ejector & $m \cdot h_{10}=m_{1} \cdot h_{6}+m_{2} \cdot h_{9}$ \\
\hline Valve & $h_{7}=h_{8}$ \\
\hline $\begin{array}{c}\text { Energy efficiency of the } \\
\text { ORC cycle }\end{array}$ & $\eta_{O R C} \frac{W_{T}-W_{P}}{Q_{G}}$ \\
\hline $\begin{array}{c}\text { Refrigeration Coefficient } \\
\text { of performance }\end{array}$ & $\eta_{C G}=\frac{W_{T}-W_{P}+Q_{E}}{Q_{G}}$ \\
\hline $\begin{array}{c}\text { Energy efficiency of the } \\
\text { cogeneration system }\end{array}$ & $Q_{G}$ \\
\hline
\end{tabular}

\section{Exergy analysis and modeling}

In energy analysis, the first law of thermodynamic is used to evaluate energy efficiency of the system but it is not sufficient to characterize the quality of energy which is also known as the exergy of the system. Therefore, the second law of thermodynamics is used in exergy analysis to evaluate the useful (noble) energy. In fact, exergy is defined as the capability of the system to produce the maximal net power and it is presented in 3 types of exergy [16]:

- Heat transferred exergy:

$$
E x_{Q}=\left|1-\frac{T_{0}}{T}\right| \times Q
$$


- Mechanical work exergy:

$$
E x_{W}=W
$$

- Matter exergy:

$$
E x_{m}=E x_{p}+E x_{k}+E x_{p h}+E x_{c h}
$$

In this work, only the variation of physical exergy is considered. It's defined by the equation below:

$$
E x_{p h}=h-h_{0}-T_{0}\left(s-s_{0}\right)
$$

It's important to define the reference temperature in the exergy analysis that defines the standard conditions of the system. Since the ambient air is the cold source for the system proposed, the ambient temperature is chosen as a reference temperature for the system which is equal to $25^{\circ} \mathrm{C}$. The total exergy destruction (Irreversibility) of the system is defined by the equation below:

$$
\dot{I}_{\text {tot }}=\sum E x_{\text {enter }}-\sum E x_{\text {exit }}+\sum E x_{Q}+\sum E x_{W}
$$

Same as the energy efficiency, we also define the exergy efficiency [15] associated to ORC cycle, refrigeration cycle and the cogeneration system given by the equations 7,8 and 9 :

$$
\begin{gathered}
\eta_{E x O R C}=\frac{W_{t}-W_{p}}{Q_{g}\left(1-\frac{T_{0}}{T_{g}}\right)} \\
\eta_{E x \mathrm{Re} f}=\frac{Q_{e v}\left(\frac{T_{0}}{T_{e v}}-1\right)}{Q_{g}\left(1-\frac{T_{0}}{T_{g}}\right)} \\
\eta_{E x \text { System }}=\frac{W_{T}-W_{P}+Q_{e v}\left(\frac{T_{0}}{T_{e v}}-1\right)}{Q_{g}\left(1-\frac{T_{0}}{T_{g}}\right)}=1-\frac{\dot{I}_{t o t}}{Q_{g}\left(1-\frac{T_{0}}{T_{g}}\right)}
\end{gathered}
$$

\section{Results and discussion}

Results obtained in energy analysis have shown that the system performance is mainly affected by the steam generator temperature and the refrigeration temperature, as shown in figure 3 .

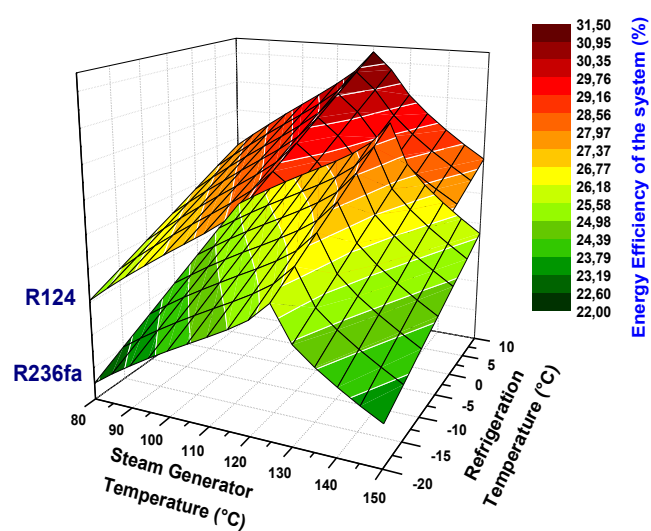

Fig. 3. System Energy efficiency as a function of the steam generator temperature and refrigeration temperature for R124 and R236fa
According to figure 123456, the energy efficiency of the system of both HCFC refrigerants R124 and R236fa is optimal at a particular steam generator temperature which is the critical temperature of each fluid. At this point, the heat consumed is minimal and the peak obtained in figure is explained by the translation from the subcritical regime to transcritical regime. However, above the critical temperature, the energy efficiency is decreasing because the refrigeration coefficient of performance is reducing.

On the other hand, results have shown that the working fluid R124 has the best performance and its energy efficiency has reached about $31,5 \%$.

Figure 4 shows the results of HFO refrigerants R1234yf and R1234ze.

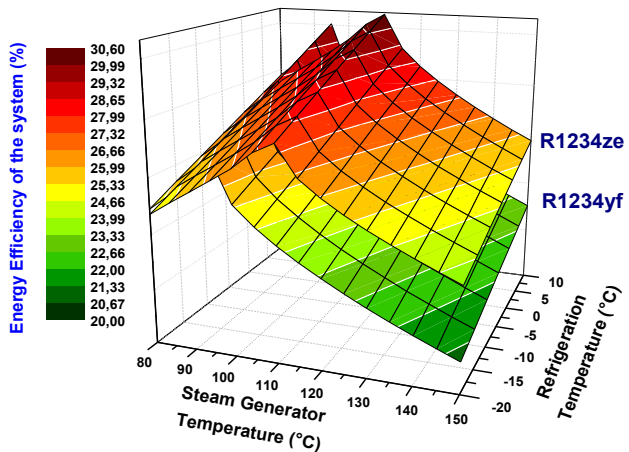

Fig. 4. System Energy efficiency as a function of the steam generator temperature and refrigeration temperature for R1234yf and R1234ze

According to figure 4, R1234yf and R1234ze have the same behavior of energy efficiency as for the refrigerants R124 and R236fa. However, the refrigerant presents the minimal heat consumed due to their low critical temperature compared to the other chosen fluids.

Besides these temperatures, the parameters of the gas ejector can be used to optimize the system performance. The influence of motive ratio and the entrainment ratio on the system energy efficiency is plotted in figure 5 .

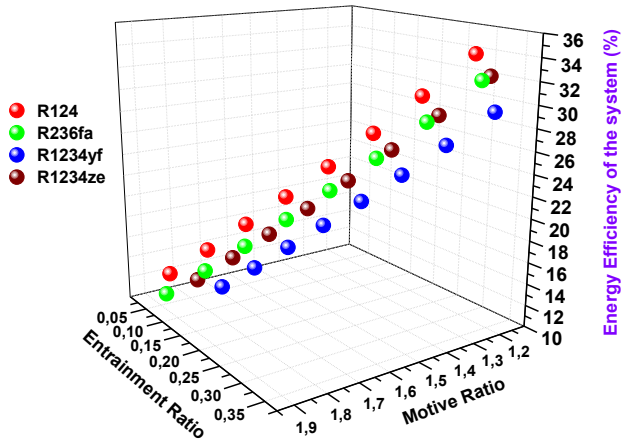

Fig. 5. Energy efficiency of the system as a function of the Entrainment ratio and the Motive ratio

According to figure 5, the energy efficiency of the system is optimized by increasing the entrainment ratio and decreasing the motive ratio. In fact, results showed that entrainment ratio is affecting only the refrigeration 
coefficient of performance which is related by the primary and secondary flows.

However, by decreasing the motive ratio, the outlet gas pressure of the turbine is decreasing. Therefore, the mechanical power produced by the turbine is enhanced. Consequently, the motive ratio has influence only on the ORC cycle efficiency. Furthermore, results showed that R124 presents the highest efficiency compared to the chosen fluids and its efficiency reaches about $35 \%$.

Meanwhile, exergy efficiency of the system is affected by the same parameters used in energy analysis. Figure 6 shows the variation of exergy efficiency as a function of the steam generator temperature and refrigeration temperature for HCFC fluids.
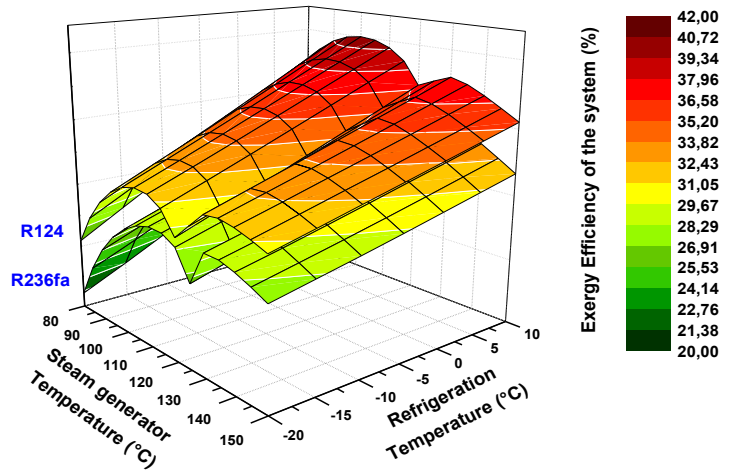

Fig. 6. System Exergy efficiency as a function of the steam generator temperature and refrigeration temperature for R124 and R236fa

Unlike the behavior of energy efficiency of the cogeneration system, the exergy efficiency is showing a minimal peak at the critical temperature for each working fluid. Exergy performance is low at this point because the irreversibility of the system is optimal. Results have shown that steam generator is presenting the highest irreversibility compared to the other components of the cogeneration system at the critical temperature. Similarly, figure 7 shows the exergy efficiency of the system for the HFO refrigerants.
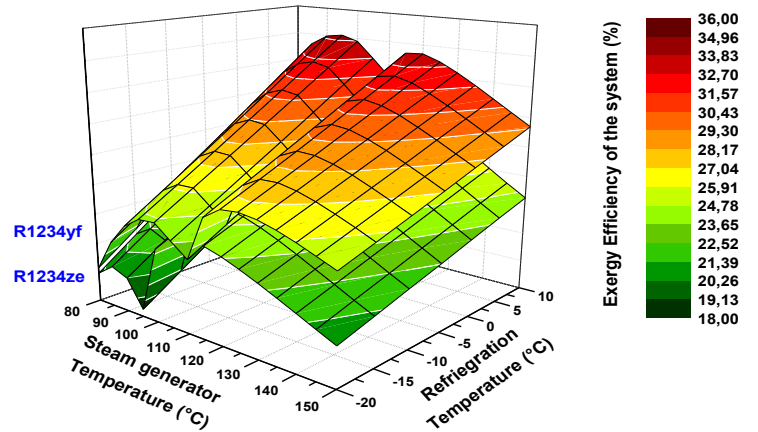

Fig. 7. System Energy efficiency as a function of the steam generator temperature and refrigeration temperature for R1234yf and R1234ze

By exploring the results plotted in figure 7, R1234yf is presenting better performance than R1234ze and its exergy efficiency has reached about $36 \%$. However, the refrigerant R124 is presenting the best system performance among the chosen fluids and its exergy efficiency has reached $42 \%$. On the other hand, the effect of the ejector parameters on exergy performance is shown in figure 8.



Fig. 8. System Exergy efficiency as a function of the Entrainment ratio and the motive ratio

According to results shown in figure 8, the exergy efficiency of the system is optimal at the highest entrainment ratio and the lowest motive ratio of the gas ejector. Similarly to energy efficiency, the entrainment ratio is affecting only the exergy of the refrigeration cycle as the motive ratio is affecting only the exergy of the ORC cycle.

As usual, the refrigerant R124 is presenting the highest exergy performance compared to others.

\section{Conclusions}

The energy and exergy study of the cogeneration system proposed in this work is realized by considering the effect of the parameters of the gas ejector. Results have shown that the integration has improved the system performance from an energy and exergy point of view.

Furthermore, the internal heat exchanger had minimized the heat consumption by saving energy recuperated from the ejector. On the other hand, a comparative study of the working fluids had demonstrated that the R124 has the highest performance among other refrigerants.

\section{References}

1. X. Zhang, M. He, Y. Zhang, Ren. \& Sus. En. Rev 16, 7 (2012), 5309.

2. D. Yogi Goswami, En. S. 20(2) (1998), 137.

3. C. Zamfirescu, I. Dincer, Therm. Ac 477, (1-2) (2008), 7.

4. S. Aghahosseini, I. Dincer, App. Th. Eng 54, 1 (2013), 35.

5. N. Shokati, F. Ranjbar, M. Yari, App. Th. Eng, 91 (2015), 479.

6. H. Chen, D.Y. Goswami, E.K. Stefanakos, Sus. En. Rev, 14 (2010), 3059.

7. R.P. Vikas, V.I. Biradar, R. Shreyas, P. Garg, S. Orosz, N.C. Thirumalai, Re. En, 113 (2017), 1250. 
8. A. Marin, A. Dobrovicescu, L. Grosu, A. Gheorghian, UPB Sci. Bull. Ser. D. 76, 4 (2014), 127.

9. A. Schuster, S. Karellas, E. Kakaras, H. Spliethoff, Appl. Therm. Eng, 29 (2009), 1809.

10. K.K. Srinivasan, P.J. Mago, S.R. Krishnan, En, 35 (2010), 2387.

11. A.M. Delgado-Torres, L. Garcia-Rodriguez, En. Conv. Man, 51 (2010), 2846.

12. D. Casrtelli, M. Binotti, P. Silva, E. Macchi, E. Roccaro, T. Passera, En. Pr, 69 (2015), 1220.

13. S. Quoilin, M.V.D. Broek, S. Declaye, P. Dewallef, V. Lemort, Ren. \& Sus. En. Rev, 22 (2013), 168.

14. PJ. Mago, LM Chamra, K Srinivasan, C. Somayaji, Appl. Therm. Eng, 28 (2008), 998.

15. O. Badr, S. D. Probert, P. W. O'Callaghan, App. En, 21 (1985), 1.

16. V. Long Le, M. Feidt, A. Kheiri, S. Pelloux-Prayer, En, 67 (2014), 513. 